Julian Krüper / Jörg Philipp Terhechte

\title{
Spielen für den guten Zweck
}

Gegenwärtige und künftige Regulierung von Soziallotterien im deutschen Recht

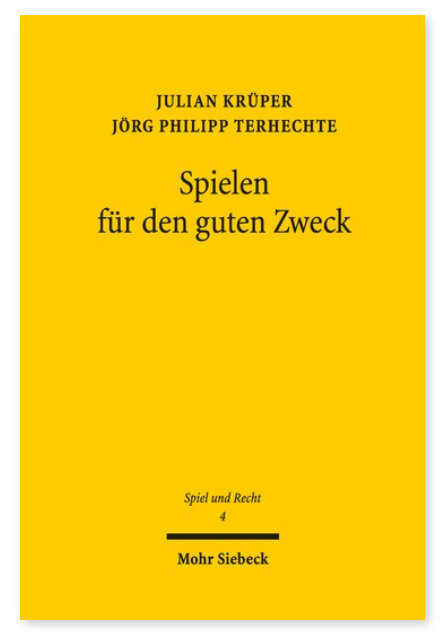

2019. VIII, 65 Seiten. SuR 4

ISBN 978-3-16-156819-0

DOI 10.1628/978-3-16-156819-0

eBook PDF $29,00 €$

ISBN 978-3-16-156818-3

fadengeheftete Broschur 29,00€
Das Recht der Soziallotterien ist reformbedürftig. Als Sonderform des Lotteriespiels unterliegen Soziallotterien gegenwärtig strengen Beschränkungen durch den GlüStV 2012. Die Autoren analysieren die geltende Rechtslage und bewerten sie am Maßstab des Grundgesetzes und des europäischen Unionsrechts. Zugleich nehmen sie rechtsvergleichend das Soziallotteriewesen in verschiedenen europäischen Ländern in den Blick. Dabei zeigt sich, dass eine Liberalisierung des Soziallotteriewesens rechtlich geboten ist, weil die gegenwärtigen Regelungen weder verfassungs-, noch unionsrechtlich gerechtfertigt werden können und auch suchtpolitisch unnötig sind. Eine Liberalisierung ist zudem gesellschaftlich wünschenswert, um die gemeinwohlförderlichen Potentiale des »Spielens für den guten Zweck« auch in Deutschland zu heben. Der Band unterbreitet dazu Eckpunkte eines Regulierungsansatzes.

Julian Krüper ist Inhaber des Lehrstuhls für Öffentliches Recht, Verfassungstheorie und interdisziplinäre Rechtsforschung an der Juristischen Fakultät der Ruhr-Universität Bochum und geschäftsführender Direktor des Instituts für Glücksspiel und Gesellschaft.

Jörg Philipp Terhechte ist Professor für Öffentliches Recht, Europäisches und Internationales Recht an der Leuphana Universität Lüneburg und Professor for European and International Economic Law an der University of Glasgow; Direktor des Leuphana Center for Gaming Law \& Culture; seit 2016 Vizepräsident der Leuphana Universität Lüneburg und seit 2018 Academic Director des European Centre for Advanced Studies GmbH.

Jetzt bestellen:

https://www.mohrsiebeck.com/buch/spielen-fuer-den-guten-zweck-9783161568190?no_cache=1 order@mohrsiebeck.com

Telefon: +49 (0)7071-923-17

Telefax: $+49(0) 7071-51104$ 